\title{
IMAGENES DE SATÉLITE Y TELEDETECCIÓN COMO HERRAMIENTA DE APOYO PARA EL DESARROLLO DE MINAS DE YESO Y ESCOMBRERAS EN EL ARARIPE
}

\author{
G. I. MACÊDO FILHO \\ Universidade Federal de Pernambuco \\ gregoriomacedo@gmail.com
}

Artículo presentado en abril/2016 y aceptado octubre/2016

DOI: $10.15628 /$ holos.2016.4492

\section{RESUMEN}

Las Herramientas de teledetección se hacen cada vez más presente en el día a día de las minerías, no sólo para la gestión de títulos de derechos minerales, más para incluso, el monitoreo y control del avance de las minas, e impactos ambientales conexos con las labores en las minas a cielo abierto. La libre disponibilidad de imágenes satelitales y de software de tratamiento de datos georreferenciados proporcionó la popularización de estas tecnologías, lo que acelera el proceso y reduce los costos de investigación. La fabricación de yeso es el principal proveedor de desarrollo económico y social en la región semiárida de Araripe, pero también es el mayor generador de impactos ambientales sobre la Caatinga. Las escombreras son capaces de causar daños de similares aquellos generados en las labores en las minas, tenidas así, como un caso importante dentro del análisis de impacto ambiental. El objetivo de este trabajo ha sido identificar y estimar el avance de las minas de yeso y escombreras ubicadas en el Polo Gesseiro do Araripe a lo largo de 15 años (1992 - 2007) sobre la Caatinga, a partir del tratamiento, análisis y clasificación de imágenes de satélite como método de apoyo a la gestión y control de los impactos ambientales.

PALABRAS CLAVE: Araripe, Minería, Teledetección, Yeso

\section{IMAGENS DE SATÉLITE E SENSORIAMENTO REMOTO COMO UMA FERRAMENTA PARA APOIAR O DESENVOLVIMENTO DE MINAS DE GESSO E ESCOMBREIRAS EM ARARIPE}

\section{RESUMO}

As ferramentas de geoprocessamento estão cada fez mais presentes no dia-a-dia da mineração, sobretudo no que diz respeito ao controle de expansão das áreas e impactos ambientais relacionados ao desenvolvimento das minas superficiais. A disponibilidade gratuita de imagens de satélite e a popularização dos softwares para processamento de dados georreferenciados facilitou o acesso a tais tecnologias, acelerando o processo investigativo e reduzindo custos. A produção de gipsita em Pernambuco é a principal atividade propulsora do desenvolvimento econômico e social no Semiárido do Araripe, mas também é a maior geradora de impactos ambientais sobre a Caatinga. Dado o seu potencial de degradação ambiental similar àquele provocado pelo desenvolvimento das minas, as pilhas de estéril resultantes do processo de extração da gipsita, merecem uma atenção considerável, dentro de um estudo de impacto ambiental. $O$ objetivo deste estudo foi o de identificar e estimar a expansão das minas e pilhas de estéril localizadas no Polo Gesseiro do Araripe ao longo de 15anos (1992 a 2007) sobre a Caatinga, a partir do tratamento, análises e classificação de imagens de satélite como método de apoio à gestão e controle de impactos ambientais causados pela atividade extrativa da gipsita no Araripe pernambucano.

PALAVRAS-CHAVE: Araripe, Gipsita, Mineração, Sensoriamento remoto. 


\section{INTRODUCCIÓN}

El Semiárido brasileño tiene un clima seco y caliente. Su suelo es arcilloso, con poca agua y pobre en materia orgánica afectan directamente la vida animal y vegetal. La Caatinga es el ecosistema dominante en el semiárido de Brasil. Único en el mondo, se extiende por 73.683.649 $\mathrm{km} 2$. Muy frágil y vulnerable a los procesos de degradación con una fuerte tendencia a la desertificación. Sin embargo, su subsuelo posee una riqueza mineral en forma de sulfato de calcio dihidratado, popularmente conocido como yeso (Aguiar, 2007).

Allá se encuentran las reservas con las mejores condiciones de aprovechamiento económico. Compuesta por depósitos evaporíticos ricos en yeso de alta pureza, la Cuenca Sedimentaria del Araripe, engloba partes de los estados de Bahía, Piauí, Ceará y Pernambuco, este el detenedor de los principales depósitos y mayor productor nacional.

La industria minera del yeso es el mayor generador de desarrollo económico y social del Semiárido de Pernambuco, pero también es uno de los grandes proveedores de impactos negativos al medio ambiente (AD-Diper, 2010).

La reducción del volumen de las escombreras es considerada un punto clave para una minería más respetosa con el medio. Las grandes escombreras deben tener un los mismos mecanismos de control y mantenimiento que los huecos, dado su potencial de degradación.

Cuantificar el avance de los huecos y escombreras sobre los áreas vecinas no pertenecientes a la finca minera a partir del análisis de los imagines de satélite mostrase bastante útil por la facilidad operacional de algunos software de tratamiento y clasificación de imágenes, además de la posibilidad de acceso gratuito a imágenes disponibles en internet.

\subsection{Aspectos económicos y sociales}

Alrededor de 300 mil personas (3,5\% de la población de Pernambuco) viven actualmente en la Región de Araripe, Nordeste de Brasil. Su PIB por habitante está alrededor de 950,00€ generados principalmente por la industria del yeso y la agropecuaria y sus derivados que son los mayores empleadores de la región. Por otro lado, el índice de desarrollo humano IDH de 0,620, está por debajo de la media nacional del 0,813 (AD-Diper, 2010).

El yeso es el principal bien mineral explotado por la industria del sector en el Semiárido pernambucano. Es el responsable por case $92 \%$ de la producción nacional en 2008 , concentrada sobre todo en 34 minas ubicadas en los municipios de Ouricuri, Ipubi, Araripina y Trindade, estado de Pernambuco, que juntas forman la zona industrial conocida como el Polo Gesseiro do Araripe (PARAHYBA et Al, 2009) (SOBRINHO et Al, 2006).

La cadena productiva del yeso en el Polo Gesseiro do Araripe abarca una vasta red formada por industrias de extracción, tratamiento y transformación del yeso, empresas de construcción civil, empresas de comercialización, distribución de yeso y productos derivados, además de sectores de apoyo a la producción mineral tales como: maquinaria y herramientas, fabricantes de explosivos, transportadoras, talleres mecánicas, hoteles, industria química e envases que generan alrededor de 13.200 empleos directos y aproximadamente 66.000 indirectos en los estados de Ceará, Piauí, Bahia y Pernambuco (PARAHYBA et Al, 2009) (SOBRINHO et Al, 2006) ((BDE, 2010). 


\subsection{Geología y área de estúdio}

Las acumulaciones de yeso se encuentran depositadas en capas discontinuas que ocurren en los Miembros Crato (inferior), Romualdo (superior) y principalmente en el Miembro Ipubí (intermediario), todos componentes de la Formación Santana de espesor promedio de $250 \mathrm{~m}$ (PARAHYBA et Al, 2009) (SOBRINHO et Al, 2006).

El yeso de Araripe pernambucano es encontrado a poca profundidad o en afloramientos lo que reduce significativamente los costos operacionales y presenta un alto grado de pureza incrementando aún más su valor. Sin embargo, la falta de una infraestructura, sobre todo en lo que se refiere a la logística de los productos, que permita la reducción de los costos de transporte, hace con que este producto llegue a los principales mercados consumidores con el coste hasta nueve veces mayor que su coste de producción, perdiendo, competitividad respecto otros países (ARAÚJO, 2007) (SOBRINHO et Al, 2006).

La Formación Santana, que es la más explotada, tiene su origen en el Cretáceo, un ambiente marino/lacustre, presentando yeso de alta calidad depositado en yacimientos de hasta $32 \mathrm{~m}$ de espesor, a profundidades máximas de $30 \mathrm{~m}$ de la superficie con reservas medidas del orden de 290.000 .000 de toneladas de yeso, ideales para la exploración minera. Tales depósitos normalmente presentan una sedimentación con secuencia estratificada, semi-horizontal, formada por limonitas, limonitas arcillosas, margas, areniscas, calizas laminadas y lulitas bituminosas en parte carbonatada o con presencia de fósiles (PARAHYBA et Al, 2009) (SOBRINHO et Al, 2006).

El área objeto del estudio, engloba los pueblos de Trindade y Ipubí con 147 Km2 (Figura 1), ubicada en la Cueca de Sedimentaria de Araripe, Microrregión del Sertão de Araripe, en Pernambuco, distante $690 \mathrm{~km}$ de la capital, Recife.

\section{REVISIÓN BIBLIOGRÁFICA}

De acuerdo con Aguiar (2007), la mayor concentración de la actividad productora de yeso se encuentra en el estado de Pernambuco y para Araújo (2004), los problemas ambientales más relevantes en el Polo Gesseiro do Araripe son la deforestación descontrolado de la vegetación nativa (Caatinga) para la producción de carbón vegetal para abastecer a las calcinadoras de yeso allí instaladas, el abandono de los huecos de minas no activas, la formación de escombreras generadas por el método de extracción adoptado por las minerías, el cambio del paisaje, mudanza de la dinámica superficial y sub-superficial y el carácter no sostenible del proceso productivo.

En Araújo (2004), la región circunvecina al Polo Gesseiro do Araripe es de extrema importancia ambiental por presentar un ecosistema bastante frágil y por detener manantiales subterráneos y superficiales del agua. El autor apunta como principales impactos ambientales negativos causados por la actividad de minería de yeso en el Polo Gesseiro de Araripe:

- Transformación del paisaje provocada tanto por la abertura del hueco de la mina como por la acumulación de material resultante de la remoción de la cubierta vegetal y de suelo depositado en la superficie;

- Degradación y contaminación del suelo por el uso de explosivos, residuos lubricantes y combustibles, drenaje/erosión, además de alteración de la composición química y remoción de los nutrientes del suelo; 
- Pérdida de la biodiversidad debida la deforestación y quemadas para apertura de del hueco de la mina y vías de acceso;

- Contaminación atmosférica (sonora, polvo y gases) y del agua generada por el uso de explosivos y movimiento de máquinas.
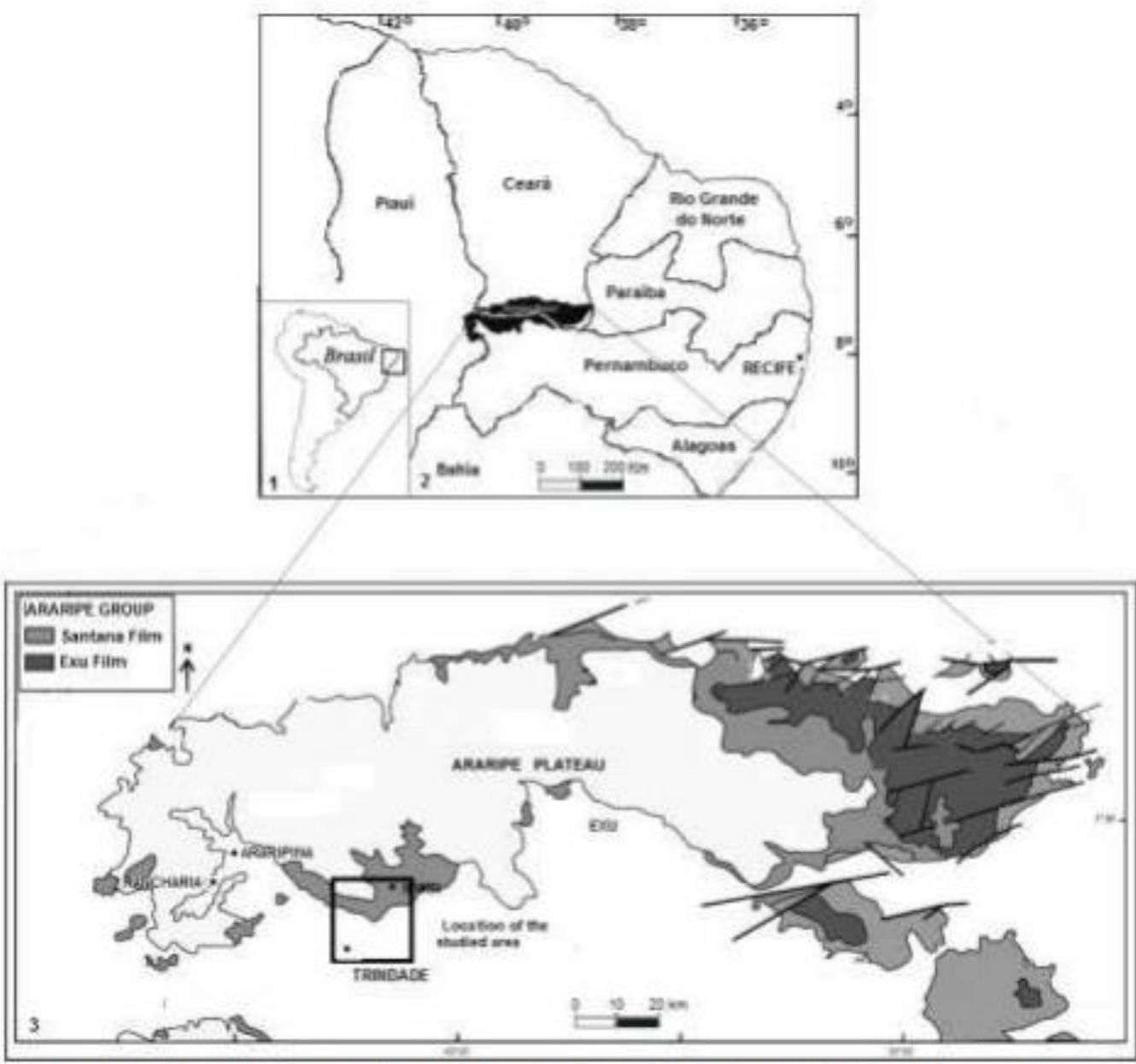

Figura 1 - Situación Brasil en Sudamérica y el área de estudio en Pernambuco.

El potencial de degradación de las escombreras es comparable al del desarrollo de la mina. Puede contaminar el suelo, el aire y el agua bajo la acción de la lluvia y viento, además altera la topografía local. Sus impactos ambientales vuelven a surtir efecto no solamente en la biota local, sino también en el rendimiento financiero de la empresa por medio del pasivo ambiental de la misma Araújo (2004).

Todos los objetos sobre la superficie de la tierra reciben radiación emitida por otros cuerpos, principalmente del sol. Esta radiación recibida puede ser: reflejada (reenviada de vuelta al espacio); absorbida (la radiación pasa a incrementar la energía del objeto y transmitida (hacia otros objetos). La teledetección es un conjunto de técnicas y herramientas computacionales que permiten obtener información de los objetos que se encuentran en la superficie de la Tierra sin contacto directo, mediante la detección de la energía electromagnética emitida o reflejada por ellos (Moraes, 2002). 


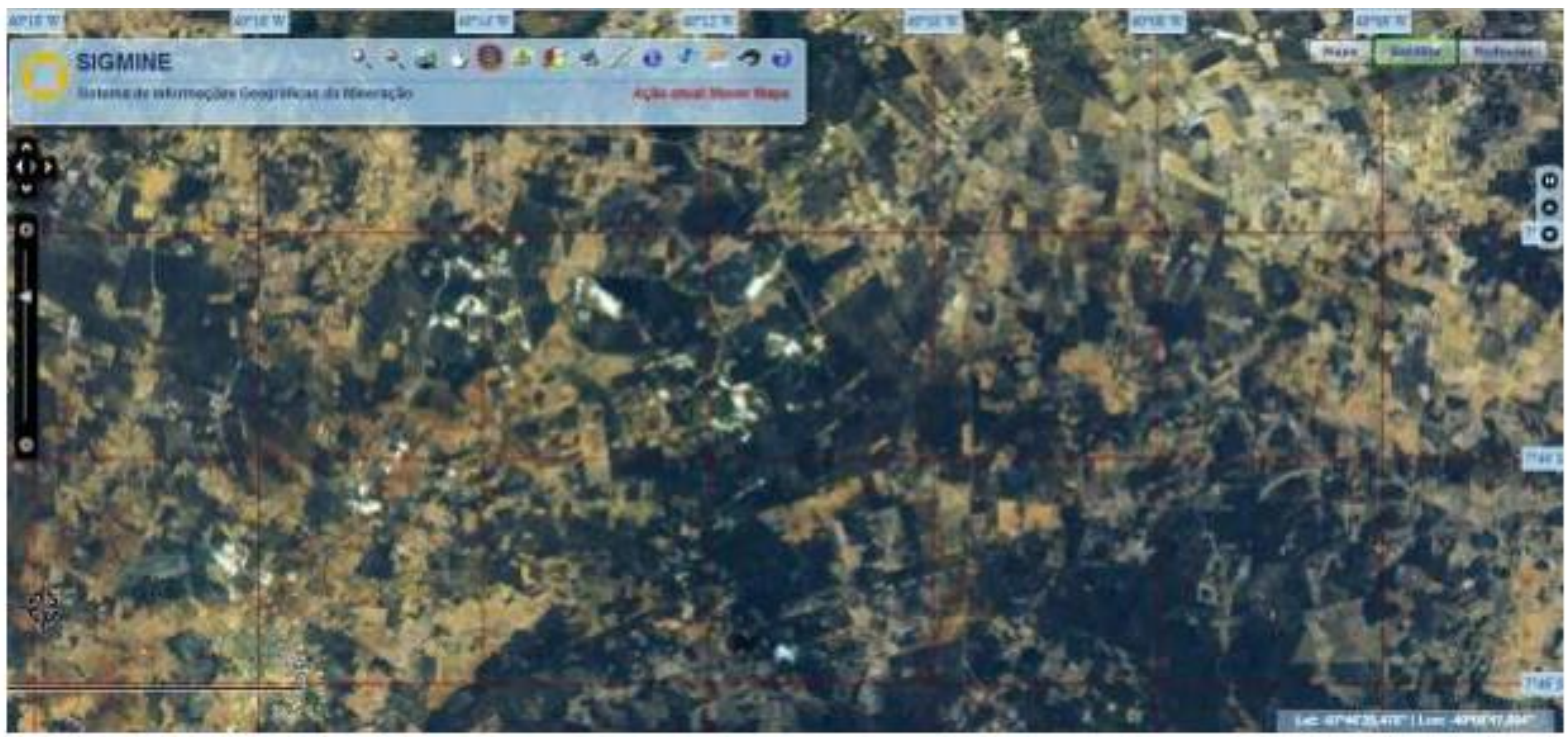

Figura 2 - Imagen del Google Earth del área del Polo Gesseiro de Araripe.

La forma como la radiación incidente es reflejada es función del tipo de objeto, depende de su superficie permitiendo distinguirlo de los demás. De esta manera, las herramientas de teledetección pueden ser aplicadas para identificar objetos y procesos en la superficie terrestre, tales como cambios en la vegetación, la calidad del agua, tipo o alteraciones en el suelo, de acuerdo con la radiación reflejada de cada objeto en diferentes longitudes de onda, la signatura espectral del objeto (Florenzano, 2007).

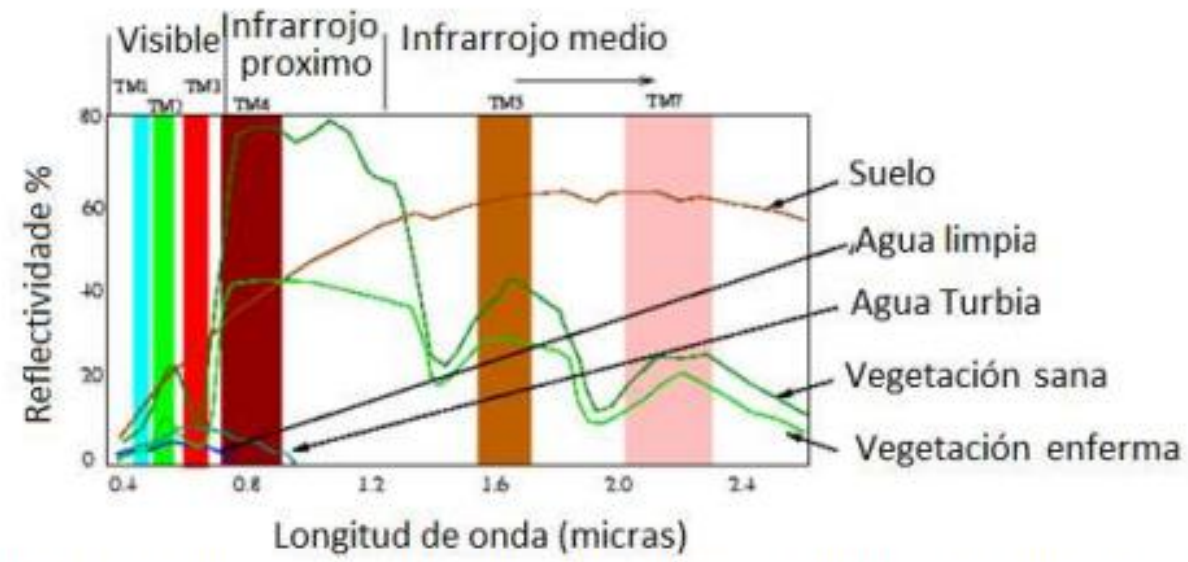

Figura 03 - Respuesta espectral de diferentes cubiertas en distintas longitudes de onda.

La remoción del revestimiento vegetal y el transporte de grandes volúmenes de tierra para expandir el hueco y viabilizar la extracción de la mena, así como la deposición del material estéril retirado de dentro de la mina provocan cambios ambientales considerables. La utilización de las técnicas de teledetección para identificar las alteraciones en la superficie provocadas por las actividades mineras a lo largo del tiempo de funcionamiento de las minas son perfectamente aplicables como herramientas de control direccional de los huecos y de crecimiento de las escombreras. 


\section{METOdOLOGÍA}

En este estudio fueron utilizadas imágenes del satélite Landsat TM, que capta la radiación refletada por cada tipo de material (suelo, roca, vegetación, agua, zona urbana, mar etc.) sobre la superficie respecto a las diferentes longitudes de onda lo que permite distinguirlos unos de los otros.

La metodología adoptada para identificar el avance de los áreas de minería sobre la Caatinga ha sido el análisis de la progresión de la degradación sobre el ecosistema, desde punto de vista biótico (vegetación) y abiótico (huecos e escombreras). Fueron utilizados dos conjuntos de imágenes de satélite de la región del Polo Gesseiro do Araripe captadas en dos períodos distintos en el tiempo separados en 15 años.

El primer conjunto de imágenes es de agosto de 1992 (figura 3) y el segundo, realizado en mayo de 2007, ambos generados por el sistema Landsat 7TM, de centro en latitud 7.2407923 y longitud 39.9063123, posteriormente reducida para imágenes con 512x512 pixeles de resolución espacial $28,5 \mathrm{~m}$.

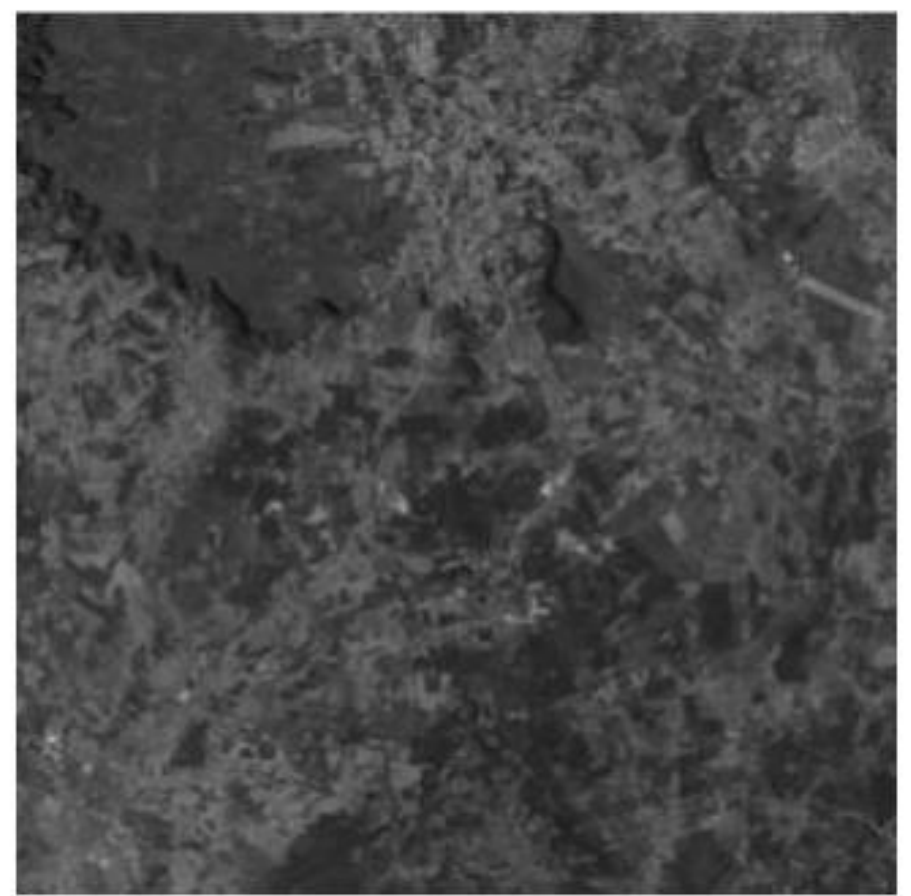

Figura 4 - Imagen del satélite Landsat 7 TM de la zona del Polo Gesseiro de Araripe.

Para realizar el estudio de clasificación de los tipos de cubiertas del suelo fue utilizado como herramienta de interpretación de imagen el software Bilko-UNESCO, con lo cual se ha hecho combinaciones de 6 de las 7 bandas espectrales para producir imágenes en falso color que mejor posibilite la visualización de los tipos de cubiertas. Las que presentaron mejor respuestas fueron las $(7,3,2)$ y $(4,5,3)$ adoptadas en el trabajo.

El proceso de clasificación de las imágenes fue dividido en dos fases de análisis para los dos conjuntos de imágenes obtenidos, donde en la primera fase se ha utilizado el método de tratamiento no supervisado que no ha presentado datos conclusivos al estudio, mientras que, el tratamiento de imagen por medio del método de clasificación supervisada ha mostrado respuestas adecuadas al estudio. En una segunda fase del análisis se optó por utilizar solamente la banda 
espectral correspondiente al infrarrojo próximo de cada conjunto de imágenes, por tener esta banda una capacidad de reflejo muy alta debido a la escasa absorción de energía por parte de las plantas.

Los resultados presentados después de finalizado los análisis de las imágenes en las dos fases del trabajos han sido semejantes.

Es posible observar que hay una reducción significativa del área clasificada como de vegetación y una expansión en el número y en la superficie de las explotaciones, como se puede ver en las Figuras 5 y 6.

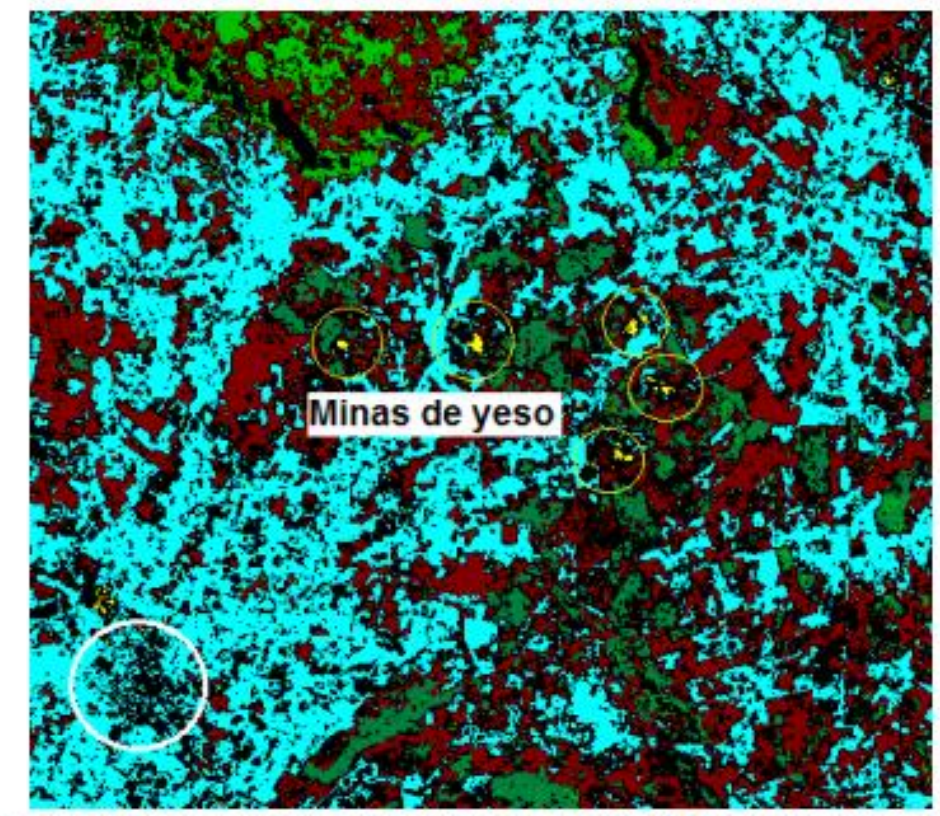

Figura 5 - Imagen del Sistema Landsat 7 TM proceso de análisis y clasificación. Polo Gesseiro de Araripe 1992.

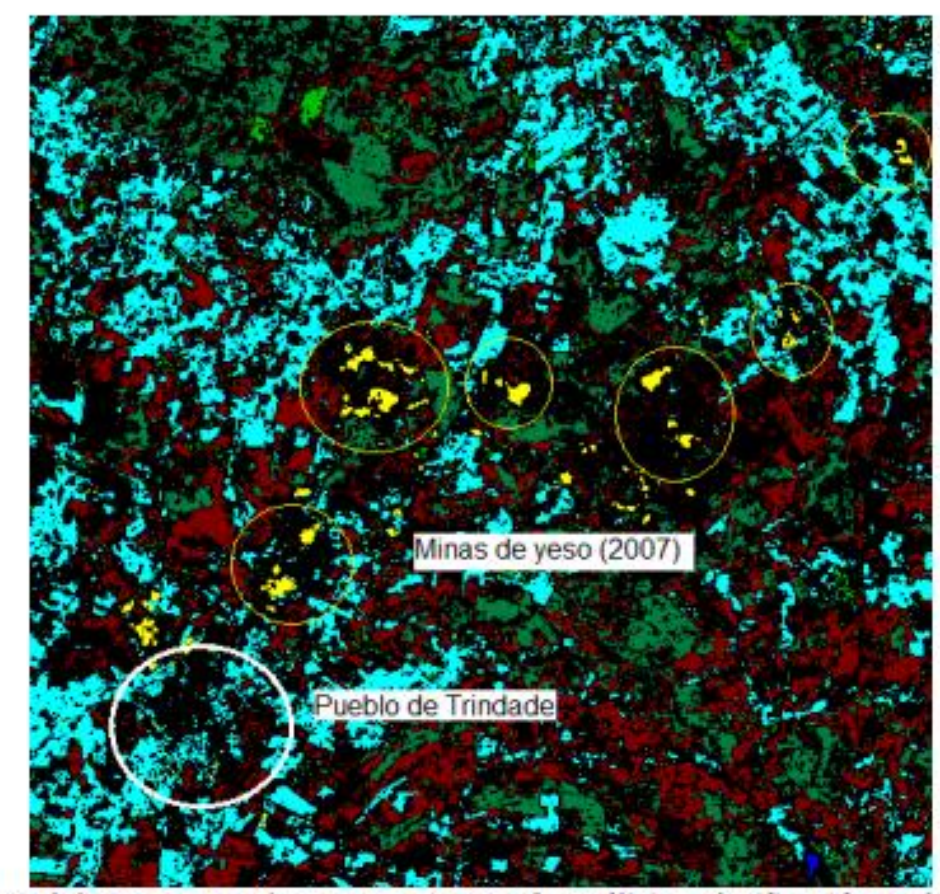

Figura 6 - Imagen del sistema Landsat 7 TM proceso de análisis y clasificación. Polo Gesseiro de Araripe วกกา 
El resultado final del procesamiento y clasificación de las imágenes seleccionadas señalan que:

1. El área cubierta por la vegetación de Caatinga nativa ha sufrido una disminución de $72 \%$ (griz oscuro);

2. Reducción de $61 \%$ del suelo agropecuaria (griz claro);

3. Aumento de $51 \%$ de suelo desnudo (en negro);

4. Expansión de $350 \%$ del área clasificada como yeso (explotación e industria de tratamiento).

La disminución del área clasificada como vegetación nativa (Caatinga) está directamente asociada al aumento de los terrenos clasificados como de explotación y tratamiento de yeso y suelo desnudo, teniendo en cuenta que aquellos caracterizados como actividad agropecuaria también han sufrido reducción de tamaño el período.

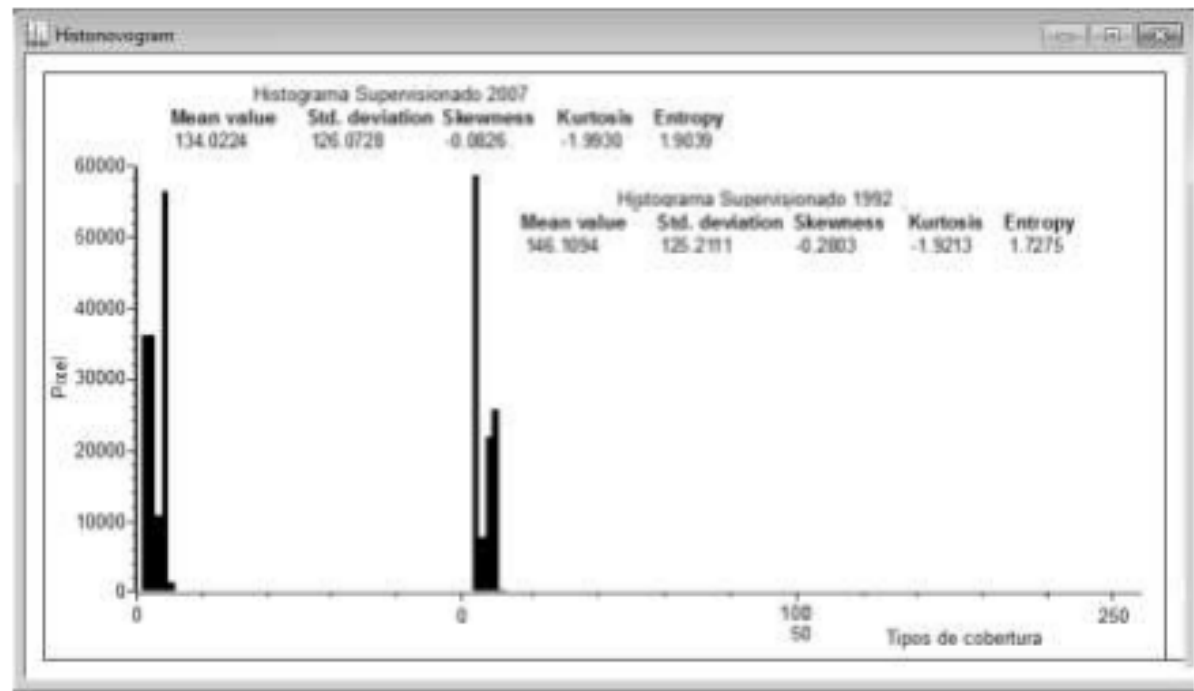

Figura 7 - Histogramas (modificados) clasificaciones 1992/2007, Bilko.

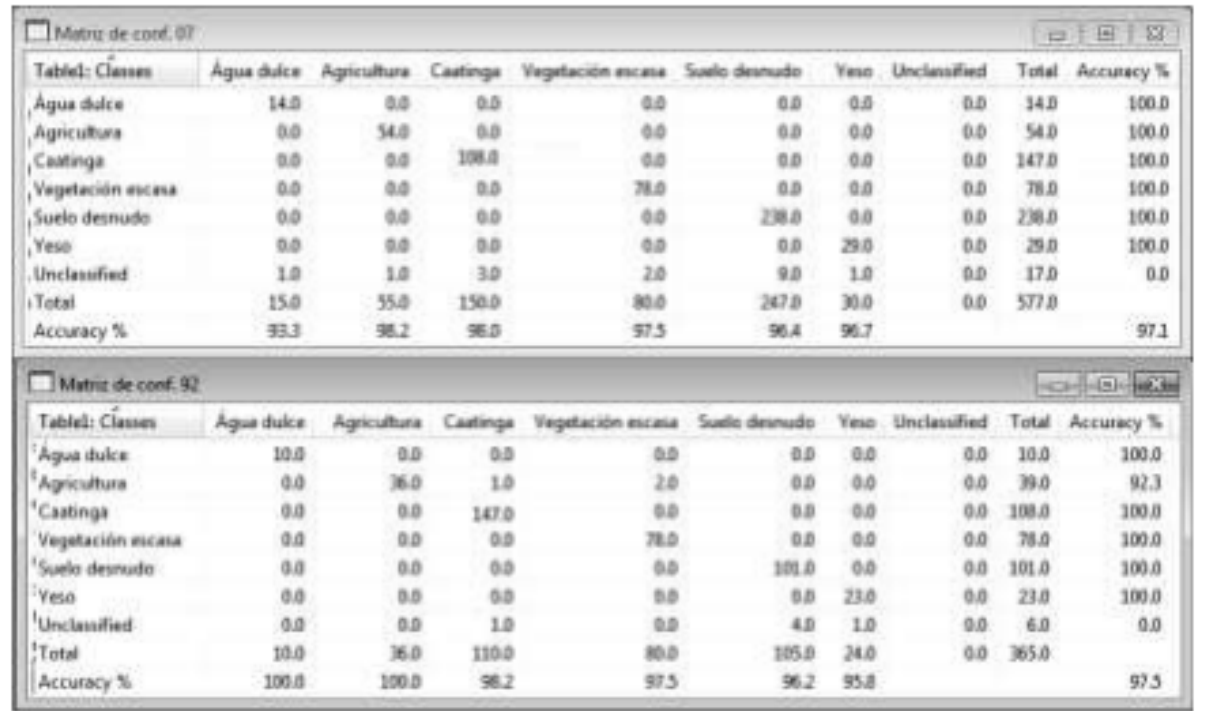

Figura 8 - Matrices de confusión clasificaciones 1992/2007, Bilko. 
Los dos conjuntos de imagines seleccionados para análisis han sido obtenidos en distintas condiciones climáticas. El año de 1992 fue parte de un largo período de 5 años de estiaje en la región, que ha afectado directamente el metabolismo de las plantas, reduciendo su fotosíntesis y la cuantidad de clorofila, como también, ocasionando la caída de las hoja, mientras que el año de 2007 ha presentado condiciones climáticas de elevado índice de precipitaciones, que favorecen el desarrollo de la vegetación.

Tales condiciones deberían presentar resultados distintos a los encontrados en este estudio, teniendo en cuenta que el principal elemento de análisis, la vegetación, habría demostrado crecimiento de su área en respuesta a las mejores condiciones climáticas en 2007.

Pero, basado en los resultados obtenidos a través del análisis de las imágenes generadas por el Bilko, se puede acreditar que la reducción del área con vegetación de Caatinga, ha sido provocada o por deforestación para el suministro de combustible para atender a la industria de producción de yeso, y por la minería, ya que no hubo expansión de la de $350 \%$ del área clasificada como explotación de yeso.

Los impactos generados por la actividad industrial del yeso, que ha triplicado durante el período de investigación.

Por lo tanto, el análisis de los imágenes de la región permite el monitoreo del avance de las minas sobre la vegetación nativa, además de valorar la eficacia de las labores de restauración ambiental en distintos periodos de tiempo.

\section{CONCLUSIONES}

Los datos climáticos registrados para la región del Sertão do Araripe en 2007 presentaron mejores condiciones para el desarrollo de la vegetación con densidad pluviométrica mayor que las presentadas en el mismo período de 1992. Luego, los datos obtenidos tras el tratamiento de los imágenes del Landsat 7 TM, deberían ser distintos a los encontrados en este estudio, teniendo en cuenta que el principal elemento de análisis en esta investigación, el cambio de la cubierta vegetal por del explotación de yeso e industria de tratamiento, habría demostrado crecimiento de su área en respuesta a las mejores condiciones climáticas ocurridas en 2007.

Pero, basado en los resultados obtenidos a través del análisis de las imágenes generadas por el Bilko, se puede pensar que la reducción del área con vegetación de Caatinga, realmente hay sido provocada por motivos de uso de la vegetación como combustible para atender a la industria de producción de yeso, o quizá por la expansión de la minería, ya que no hubo expansión de la actividad agropecuaria.

Lo que se ha podido verificar acerca de los impactos generados por la actividad industrial del yeso, es que se ha triplicado el área requerida por este tipo de actividad, y así, por supuesto, el impacto generado por la actividad de estas empresas en la región.

De este modo, resulta razonable decir que la reducción de las áreas clasificadas como vegetación nativa (Caatinga) está asociada a los resultados obtenidos con relación a la expansión de las áreas explotación de yeso e industria de tratamiento.

La adopción de una sistemática para interpretación de imágenes de satélite permitirá la formación de una base de datos actualizada y en tiempo real compartida por varios sectores dentro 
de la empresa, que sirve como una herramienta importante en la toma de decisiones empresariales.

\section{REFERENCIAS}

1. Agência de Desenvolvimento Econômico de Pernambuco (AD Diper). Regiões de desenvolvimento de Pernambuco: RD Sertão do Araripe. 24/02/2010. http://www.addiper.pe.gov.br

2. GUIAR, L. R. Avaliação da ecoeficiência de programas e projetos ambientais voltados às micro e pequenas empresas do Polo Gesseiro do Araripe, Recife, 2007.

3. Dissertação de mestrado-Departamento de Gestão e Políticas Ambientais, Universidade Federal de Pernambuco, p 156, 2007. 3. ARAúJO, S. M. S. O Polo Gesseiro do Araripe: unidades geo-ambientais e impactos da mineração, Tese de doutorado-Instituto de Geociências, Campinas, 2004, Universidade Estadual de Campinas, p 259, 2004.

4. Base de dados do Estado (BDE). Região de Desenvolvimento do Araripe. Secretaria de desenvolvimento de Pernambuco. 24/02/2010. http://www.bde.pe.gov.br.

5. FlOREnZANO, T. G., Iniciação ao Sensoriamento Remoto, São Paulo, 2007, Cap. 01, 2a ed., Oficina de Textos 128 páginas, 2007.

6. MORAES, E. C., Fundamentos de Sensoriamento Remoto, São José dos Campos, 2002, Cap. 01, 23 pag., Instituto Nacional de Pesquisas Espaciais, INPE-8984-PUD/62, 2002.

7. PARAHYBA, R. E. R.; CAVALCANTI, V. M. M.; PERLATTI, F. Mineração no Semiárido Brasileiro, Diretoria de Desenvolvimento e Economia Mineral - Departamento Nacional de Produção Mineral - DNPM. Brasília, 2009.

8. PINHEIRO, TAÍS S. DE M.; BITTAR, SHEILA M. B.; SILVA, YGOR J. A. B.; MORAES, FELIPE G. D. \& SANTOS, MONALIZA A, Características Físicas e Mineralógicas do Estéril da Mineração de Gipsita do Araripe, Recife, 2009,

9. Universidade Federal Rural de Pernambuco, 2009. 9. SOBRINHO, A.C.P.L.; AMARAL, A.J.R. y DANTAS, O.C. Sumário mineral 2006. Gipsita. Departamento Nacional de Produção MineralDNPM. Brasília, p. 175-179, 2006. 